\title{
Actores políticos e intereses en juego durante las guerras civiles del periodo federal colombiano (Santander, 1860 - 1890)*
}

Artículo recibido: 18-08-2015 / Artículo modificado: 20-2-2016/Artículo aceptado: 28-4-2016

\section{Nectalí Ariza Ariza}

Doctor y Magíster en Historia de América de la Universidad Pablo de Olavide (España), Especialista en Ciencias Políticas de la Universidad Autónoma de Bucaramanga, Especialista en Cooperación Internacional al Desarrollo de la Universidad de las Islas Baleares (España) e Historiador de la Universidad Industrial de Santander. Docente del Área de Historia colonial en la Escuela de Historia de la Universidad Industrial de Santander (Colombia). Integrante del Grupo de investigaciones históricas sobre el Estado nacional colombiano (Categoría D de Colciencias). Entre sus publicaciones recientes están: "Los pecados públicos de doña Luisa Llerena y la justicia del rey en Cartagena de Indias a mediados del siglo XVIII", Anuario de Historia Regional y de las Fronteras. 20: 1 (2015) 97-122, y "Los Wilches Calderón: red familiar y poder político en el Estado de Santander 1857-1886", Anuario Colombiano de Historia Social y de la Cultura41.2 (2014): 23-64. Correo electrónico:neariza@uis.edu.co

Referencia para citar este artículo: Ariza Ariza, Nectalí. "Actores políticos e intereses en juego durante las guerras civiles del periodo federal colombiano (Santander, 1860 - 1890)". Historia y Espacio 47 (2016): 15-40.

\footnotetext{
* Artículo Tipo 2: de reflexión según clasificación de Colciencias. Este artículo es un avance del proyecto de investigación en curso titulado "Los caudillos militares colombianos de la segunda generación, 1853 - 1902" (Código: 1879), financiado por la Vicerrectoría de Extensión e Investigación de la Universidad Industrial de Santander.
} 


\section{Actores políticos e intereses en juego durante las guerras civiles del periodo federal colombiano (Santander, 1860 - 1890)}

Resumen: En este artículo se hace una revisión general de hechos acaecidos durante las guerras civiles en Santander en el periodo federal $(1860,1876,1885)$, y se identifican líderes cuyos apellidos figuraron, tanto en las batallas como en otros escenarios decisorios de la política durante las confrontaciones. Se indaga por sus intereses y se reseñan prácticas, de orden legítimo, como algunas trasgresoras y violentas. Metodológicamente, se consultaron noticias oficiales del gobierno central y del Estado de Santander, notas de prensa, correspondencia y memorias. El artículo insiste en una vía de investigación a partir de los actores políticos regionales y locales, para conocer su capacidad de agencia y profundizar en el conocimiento de la vida política de la segunda mitad del siglo XIX.

Palabras clave: guerra civil, violencia, Iglesia, política, familias del poder, partidos, facciones.

\section{Political Agents and Political Incentives During the Wars of the Colombian Federal Period (Santander, 1860-1890)}

Abstract: This article provides an overview of the events occurred during the civil wars in Santander in the federal period $(1860,1876,1885)$, to identify leaders whose names figured in both battles and other decision-making scenarios during the confrontations. We explore their interests and practices of legitimate order, as some transgressive and violent. Methodologically, official news from the central government and the State of Santander, press releases, correspondence and reports were consulted. The trial insists on a research agenda from regional and local political actors for their ability agency and to deepen the knowledge of the political life of the second half of the nineteenth century.

Key Words: War, Violence, Church, Politics, Families of Power, Parties, Factions.

\section{Atores politicos e interesses envolvidos durante as guerras civis do período federal colombiano (Santander, 1860 - 1890)}

Resumo: Este artigo é uma revisão geral dos acontecimentos das guerras civis em Santander (Colômbia) no período federal $(1860,1876,1885)$, identificando líderes cujos nomes apareceram tanto nas batalhas quanto em outros cenários decisivos da política durante as confrontações. Indaga-se sobre seus interesses e se referem práticas legítimas e outras transgressoras e violentas. Metodologicamente foram consultadas notícias oficiais do governo central e do antigo Estado de Santander, matérias jornalísticas, correspondência e memórias. O artigo insiste em uma via de pesquisa a partir dos atores políticos regionais e locais para conhecer sua capacidade de agência e para aprofundar no conhecimento da vida política da segunda metade do século XIX.

Palavras-chave: guerra civil, violência, Igreja, política, famílias do poder, partidos, facções. 


\section{Introducción}

Las guerras civiles decimonónicas de Colombia representan un campo historiográfico con tradición y énfasis temáticos recurrentes, si bien con algunas diferencias. De la guerra de 1860, se ha planteado que tuvo origen en la lucha por la soberanía de los Estados liberales contra el proyecto centralista de los conservadores ${ }^{1}$. No obstante, esta guerra también estuvo mediada por los intereses y participación de la Iglesia Católica, como se muestra en este artículo y muchos otros. De la guerra de 1876 sobresalen los trabajos acerca de la actuación del clero, que enfrentaba el laicismo impulsado por los liberales ${ }^{2}$. De la guerra de 1885 se ha analizado la división de los liberales y la reacción de la facción radical que intentó recuperar el poder político perdido. Otro centro de interés son las batallas llevadas a cabo en el entorno del río Magdalena, y el consabido resultado que enterró el proyecto federal $^{3}$. Otros trabajos han analizado las fuentes del periodo, la iconografía e incluso han compilado la narrativa literaria de las guerras ${ }^{4}$.

Los énfasis analíticos que tratan la lucha de las facciones, las elecciones, y la cuestión religiosa, están presentes en la mayoría de los estudios, desde la guerra de 1840 hasta la de los Mil días. En el conjunto de lo escrito no se pueden soslayar las investigaciones que hacen énfasis en aspectos sociales, uno de estos, la participación de sectores subalternos y de las mujeres ${ }^{5}$. La amplitud de lo

1 Para el caso de Antioquia, se puede consultar: Teresa Uribe de Hincapié y Liliana María López Lopera, La guerra por las soberanías. Memorias y relatos de la guerra civil de 1859-1862 en Colombia (Medellín: La Carreta Editores, 2008).

2 Luis Javier Ortiz, Ganarse el cielo defendiendo la religión. Guerras civiles en Colombia, 1840- 1902 (Medellín: Unibiblos, 2005); Luis Javier Ortiz, Obispos, Clérigos y fieles en pie de guerra: Antioquia, 1870-1880 (Medellín: Editorial Universidad de Antioquia, 2010).

3 Malcolm Deas, “Pobreza, guerra civil y política: Ricardo Gaitán Obeso y su campaña en el río Magdalena en Colombia, 1885”, en Del poder y la Gramática (Bogotá: Tercer Mundo Editores, 1993) 121-173; Juan Carlos Echeverri Álvarez, Juan Carlos, (2009), “La guerra de 1885 en Colombia ¿crónica de un suicidio anunciado?”, Revista de Historia y Ciencias Sociales, 16 (2009): 67-81; Gonzalo España, La guerra de 1885, Núnez y la derrota del radicalismo (Bogotá: El Ancora Editores, 1985); Julio Palacio, La guerra de 1885 (Bogotá: Editorial Cromos, 1936).

4 Brenda Escobar Guzmán, "La guerra de los Mil Días vista a través de las memorias”, en Ganarse el cielo defendiendo la religión. Guerras civiles en Colombia, 1840-1902, ed. Luis Javier Ortiz (Bogotá: Universidad Nacional de Colombia, 2005), 465-480; Diana Luz Ceballos Gómez, "La guerra de los Mil Días vista a través de las memorias”, en Ganarse el cielo defendiendo la religión. Guerras civiles en Colombia, 1840-1902, ed. Luis Javier Ortiz (Bogotá: Universidad Nacional de Colombia, 2005), 62-95; Gonzalo España, Arbey Atehortúa y Mario Palencia Mario, Narrativa de las guerras civiles colombianas (Bucaramanga: Ediciones Universidad Industrial de Santander, 2003).

5 Juan Carlos Jurado Jurado, “Soldados, pobres y reclutas en las guerras civiles colombianas”. en Ganarse el cielo defendiendo 
producido en torno a las guerras es vasto y escapa a los objetivos de este artículo, en el que modestamente se llama la atención sobre la permanencia de algunos actores, y cuando no, de sus parientes, en el conjunto de confrontaciones dadas en Santander durante la segunda mitad del siglo XIX, de manera que cabe preguntar si se trató de una única guerra civil con diferentes fases.

Puede afirmarse que los hechos generales de las guerras civiles del siglo XIX, coinciden en los trabajos referenciados con más o menos precisión. Por tanto, no se reparará en los mismos, si bien se traen al texto algunos memorables, simplemente para observar la persistencia de los líderes y sus parientes, sus prácticas, y en parte, los intereses que defendían, pues quizá, más allá del ideal de Estado que los jefes políticos exponían, estaba el control de los cargos, del fisco, y de la riqueza que el aparato político de los estados facilitaba. Ahora bien, del conjunto de las confrontaciones, se conocen los jefes del orden nacional, y en parte de los estados, pero poco se sabe de los jefes de familias de las provincias y localidades. Por esto es válido preguntar cómo se articularon en las guerras, qué intereses defendían y qué prácticas implementaron durante y después de las batallas.

\section{La revolución conservadora de 1860}

La Guerra de las Soberanías, conocida como de 1860, que se prolongó hasta avanzado el año de 1862, comenzó en la región santandereana un par de años antes, justo cuando sus provincias organizaron el Estado de Santander a finales de 1857. Al año siguiente, comenzaron los amotinamientos en varias de sus poblaciones. En septiembre se supo que Habacuc Franco, el alcalde conservador de Charalá, repartió armas entre la población. En febrero del siguiente año, Juan J. Márquez, un oficial del ejército de la Unión, se alzó en armas en Onzaga. El mismo mes, Leonardo Canal, jefe de los conservadores en el norte de Santander e Intendente de Hacienda del gobierno nacional, lideraba en Pamplona una guerrilla de un centenar de hombres; y en Málaga el cura Fructuoso Ortiz y su hermano, el hacendado Salustiano, alistaron cerca de cincuenta guerrilleros ${ }^{6}$. En Girón, población vecina de Bucaramanga, se alzaron en armas los notables Blas Hernández, Crisóstomo Ordóñez y Adolfo Harker. En una proclama que hicieron el dos de marzo, después asaltar y tomar la ciudad del Socorro, señalaron entre sus motivos la burla del sufragio, la omnipotencia de la Asamblea, la eliminación jurí-

la religión. Guerras civiles en Colombia, 1840-1902, ed. Luis Javier Ortiz (Bogotá: Universidad Nacional de Colombia, 2005), 465480; Gloria Arango de Restrepo, "Las mujeres, la política y la guerra vistas a través de la Asociación del Sagrado Corazón de Jesús. Antioquia, 1870-1885 en Ganarse el cielo defendiendo la religión. Guerras civiles en Colombia, 1840-1902, ed. Luis Javier Ortiz (Bogotá: Universidad Nacional de Colombia, 2005), 357- 444; Ana Patricia Ángel Correa, "Actores y formas de participación en la guerra vistos a través de la literatura”, en Ganarse el cielo defendiendo la religión. Guerras civiles en Colombia, 1840-1902, ed. Luis Javier Ortiz (Bogotá: Universidad Nacional de Colombia, 2005), 445-461.

6 Gaceta de Santander, 13 de septiembre, 1859, 359-360. El hacendado Salustiano Ortiz, jefe conservador de Málaga, fue constituyente suplente durante la creación del Estado en 1857. Ély su hermano, el cura Fructuoso Ortiz, lideraban a sus copartidarios de Málaga en marzo de 1858 cuando comenzaron los enfrentamientos entre liberales y conservadores. 
dica del municipio, el abandono de los caminos, el cierre de las escuelas, la conculcación del derecho de propiedad, la abolición de la pena de muerte, entre otros reclamos ${ }^{7}$.

Los rebeldes conservadores protestaban contra la ley electoral, el impuesto único a la riqueza, y contra la ley de municipios ${ }^{8}$, sobre todo contra la Ley electoral, pues fijó que todas las autoridades de las localidades serían electas por la Asamblea de mayoría radical, una cuestión sensible dado el control que ejercían los caciques en cada localidad; otros argumentos de los revoltosos fueron la libertad de culto y de educación, pues en esta última el Estado solo asumiría responsabilidad en la primaria; los conservadores también rechazaban el abandono de las carreteras, que los radicales consideraron un asunto privado de los ciudadanos, y en parte de los municipios. De igual manera, causó rechazo la amnistía total a presos y otros argumentos que con mucha imaginación tuvieron eco en la población y desacreditaban al gobierno radical ${ }^{9}$.

Los revolucionarios vencieron en poco tiempo, dado que los radicales no habían organizado ejército alguno, pues lo consideraban innecesario, y habían asumido que dada la libertad absoluta decretada por su gobierno, nadie se levantaría contra el mismo, por esto tuvieron que defenderse con una milicia que alistaron apresuradamente. En abril de 1859 los conservadores habían tomado las principales ciudades, incluida Bucaramanga, la capital del Estado, donde organizaron un gobierno dirigido por Leonardo Canal.

Al comienzo de la revuelta, los radicales dudaron acerca del apoyo dado a los rebeldes por parte del presidente de la Unión, Mariano Ospina. Al respecto, el conservador Adolfo Harker, comerciante de Bucaramanga, quien participó en el levantamiento de Girón al lado de Blas Hernández y que hizo parte del gobierno organizado por los conservadores entre abril y mayo de 1859, así como en los posteriores, escribió en sus memorias que antes del alzamiento armado se había reunido en dos oportunidades con el presidente Ospina, y que este no solo se negó a apoyarlos, sino que intentó detener el levantamiento ${ }^{10}$. Pero Harker era un conservador convencido y es factible que quisiera sostener la versión oficial de la época, así escribiese unos años después.

7 Adolfo Harker, Mis recuerdos (Bucaramanga: Academia de Historia de Santander, 1954), 46. Los diferentes amotinamientos y la guerra pueden seguirse en la Gaceta de Santander; también en las memorias de contemporáneos como Adolfo Harker, quien participó directamente en el levantamiento de Girón y en las escaramuzas posteriores. Otro testigo de los hechos fue el cronista -también conservador- José Joaquín García. Crónicas de Bucaramanga (Bucaramanga: Imprenta y Librería de Medardo Rivas, 1896). 8 Gaceta de Santander, 25 noviembre, 1857, 41.

9 David Church Johnson, Santander siglo XX. Cambios socioeconómicos (Bogotá: Carlos Valencia Editores, 1984) 56-57. Johnson cita los textos tendenciosos publicados en la Voz del Norte, por ejemplo, del primer artículo de la Constitución, que rezaba "El Estado de Santander se compone de todo hombre que pise su territorio". Se dijo que convertiría a Santander en refugio de aventureros y criminales de todo el mundo, que quizá acabaran por controlar el gobierno; como se criticaba el derecho de asociación y que no se limitara el porte de armas, se profetizaba que bandas armadas asolarían los campos; de la libertad de cultos, decían que llevaría a la "poligamia oriental", y que en todos los pueblos aparecerían estatuas de Marte y Venus, etc.

10 Adolfo Harker, Mis recuerdos, 46-47. 
Los radicales se convencieron de la participación de Ospina, porque se supo que sus agentes distribuyeron las armas del gobierno central entre los rebeldes ${ }^{11}$, y porque todos los funcionarios dependientes del gobierno nacional se vincularon de diferentes modos a la revolución conservadora. Así por ejemplo, antes de que se produjesen batallas significativas, algunos ricos comerciantes de Cúcuta y Maracaibo (Felipe Arocha, comerciante de Maracaibo, Silvestre Serrano y Joaquín Estrada) informaron con detalle acerca de los promotores de la revolución en Pamplona y Cúcuta. Señalaron que desde la aduana salían guardas de posta con comunicaciones para los revolucionarios, y que entre los jefes estaban: Sinforoso Mutis, comandante de resguardos; Pedro Peralta Rodríguez, administrador de correos nacionales; el contador, Luis A. Granados; el oficial de intendencia, Teófilo Moncada; el Intendente de Hacienda, Leonardo Canal; el oficial escribiente y otros ${ }^{12}$. Todos ellos aparecieron involucrados en las batallas y fueron tomados prisioneros varias veces. Los comerciantes también denunciaron que uno de los jefes de los revolucionarios era el presbítero Francisco Romero.

Entre mayo y junio de 1859, las fuerzas alistadas en Santander, al mando de Eustorgio Salgar, derrotaron a los rebeldes y retomaron el control de las ciudades. La asamblea reinició sesiones en Bucaramanga el 20 de junio y ratificó a Salgar como presidente. Este, en su intervención ante la asamblea señaló lo que era un secreto a voces: que los agentes del gobierno central habían repartido armas y brindado apoyo desde un comienzo a los revolucionarios. Recordó que el jefe militar de las fuerzas rebeldes, el Coronel Márquez, era un oficial del gobierno central; y lamentaba que muchos de los funcionarios del gobierno de Santander, como alcaldes, jueces parroquiales, fiscales y agentes recaudadores de las poblaciones conservadoras, hubiesen robado las contribuciones del impuesto directo, sumándose a los rebeldes ${ }^{13}$. Ante las circunstancias el presidente de Santander, Eustorgio Salgar tomó medidas para superar las causas de la rebelión y convocó la segunda constituyente para el mes de noviembre de ese año. Mientras tanto la Asamblea aprobó varias leyes para quitar motivos a los revolucionarios. Así por ejemplo, con una Ley de 25 de junio se dividió el territorio en ocho departamentos (Soto, García Rovira, Pamplona, Cúcuta, Ocaña, Vélez, Socorro y Guanentá), cada uno de éstos tendría un jefe departamental, del cual dependería el nombramiento y remoción de alcaldes. De tal modo se empezaba a descentralizar el poder de la Asamblea, uno de los reclamos y

11 Gaceta de Santander, julio 16, 1858, 177, 179 .

12 Gaceta de Santander, 11 de agosto, 1859, 349-350.

13 Gaceta de Santander, 20 de junio, 1859, 319-321. En una comunicación oficial el presidente Salgar increpaba a Ospina para que detuviera su intervención en Santander, le exigía que frenara el apoyo del gobierno de Boyacá, pues en ese Estado tenían su retaguardia los rebeldes. Ospina respondió que la rebelión era exclusiva de Santander y no una guerra entre Estados, que las leyes de Santander le impedían actuar, dada la soberanía decretada por los radicales; además le recordó a Salgar que en Santander se había declarado el derecho a la rebelión. Se trataba del mismo argumento expuesto por Rito Antonio Martínez, jefe conservador de San Gil. 
motivo del levantamiento ${ }^{14}$. A finales de año, ya con una nueva Constitución, fueron establecidos los delitos de rebelión, sedición, motín y asonada; también se prohibió la reunión de personas armadas. La rebelión convenció a los radicales de la necesidad de contar con alguna fuerza militar, por esto la Asamblea decretó el alistamiento de una fuerza de 2.200 hombres, de los cuales 700 serían de servicio permanente y estarían distribuidos entre Málaga, San Gil, Cúcuta y Pamplona, las ciudades donde había estallado la revuelta.

En agosto de 1859, mientras los radicales reorganizaban el gobierno y preparaban la Constituyente, los conservadores emprendieron otro ataque desde Boyacá. Unos 900 hombres en armas, reorganizados y al mando del coronel Melchor Corena, intentaron tomar la población de La Concepción, capital de la provincia de García Rovira, el 29 de agosto, siendo derrotados por fuerzas del Coronel Santos Gutiérrez, cuyas tropas capitaneaban los jefes de la familia Wilches Calderón: Solón y sus primos Joaquín Calderón y Milciades Wilches. Esa era la segunda batalla dada en esa ciudad, pues en abril había sido atacada por unos ochenta guerrilleros que dirigía el mencionado guerrillero malagueño Salustiano Ortiz Santos, quien había sido capturado y amnistiado, pero igual que los demás, había vuelto a alistarse en armas. Un parte de David Díaz Granados, jefe departamental de la provincia, dio cuenta de los resultados de la batalla de agosto: los conservadores tuvieron 91 muertos y fueron detenidos todos sus jefes, entre los que se contaban los cuatro hermanos Canal (Leonardo, Ezequiel, Pedro León y Manuel Francisco), y el presbítero Andrés Blanco. Entre los del gobierno habían muerto 44 hombres, y hubo más de 73 heridos, sumados los de uno y otro bando ${ }^{15}$.

Con la relativa calma establecida, los radicales encabezados por Salgar convocaron las elecciones de diputados para el mes de octubre. La nueva asamblea resultó liberal en su totalidad, pues los conservadores no participaron. El 23 de noviembre de 1859 los asambleístas tomaron posesión de sus cargos y nombraron a Victoriano de Diego Paredes como su presidente, y enseguida abordaron la reforma constitucional, de modo que al mes siguiente expidieron una nueva carta, la tercera ${ }^{16}$.

Entre las leyes que votaron, una del 23 de diciembre trataba de la forma en que se organizarían las elecciones. Un tema que parecía ser "manzana de discordia" con el gobierno central, pues este había expedido una Ley el 8 de abril anterior, que fue rechazada en la mayoría de los estados. Los radicales procuraron ser "políticamente correctos" y dijeron que aceptaban la Ley electoral de Ospina, pero reformándola. Tal lo hicieron ese 23 de diciembre. La Ley del 8 de abril había sido pensada para controlar las elecciones, pues contemplaba que las Juntas electorales de los estados deberían ser nombradas por el Congreso y el presidente. Su tarea sería la de organizar las elecciones a la Presiden-

14 Gaceta de Santander, 3 de agosto, 1859, 343-348.

15 Gaceta de Santander, 13 de septiembre, 1859, 359-360.

16 Gaceta de Santander, 31 de diciembre, 1859, 397. 
cia de la Unión y al Congreso, también estarían encargadas de los escrutinios. La diferencia entre los dos gobiernos era básica y definitiva: cada uno reclamaba el derecho a decidir los nombres de los integrantes de las juntas. Los radicales aceptaban la división del territorio en círculos electorales y que las Juntas escrutaran, pero agregaron que las juntas serían nombradas por la Asamblea del Estado, y no desde Bogotá. Su propuesta se puso en práctica en junio de 1860, en las elecciones de diputados; y como se puede suponer, en Santander todo el aparato electoral quedó bajo control de los radicales. Las juntas muestran a las familias liberales que controlaban políticamente cada una de las regiones: en García Rovira, el clan de los Wilches; en Ocaña, cuatro miembros de la familia Jácome, dos de los Quintero, y dos Lobo, apellidos que además estaban emparentadas entre sí; en Pamplona aparecen dos Villamizar Gallardo, dos Contreras, dos Hernández, y así sucesivamente.

La ley nacional electoral de 8 de abril quedó registrada en la historiografía nacional como la primera causa de la guerra, y pudo ser, pero se sumó a otras circunstancias. Quizá la ley fue el punto de inflexión, pues Ospina y sus copartidarios querían controlar las elecciones a la presidencia y al Congreso, obviamente para seguir gobernando. El gobierno central alegaba que era una manera de frenar el fraude en los estados, pero el argumento de los liberales era justamente lo contrario: que era una forma de organizarlo por parte de los conservadores. Los radicales consideraron además que se trataba de una agresión a la soberanía de los estados federales ${ }^{17}$. Ante la resistencia y reclamos de los estados, Ospina siguió adelante con otras leyes para ampliar el pie de fuerza y para intervenir en los conflictos internos de los estados ${ }^{18}$.

El enfrentamiento entre los gobiernos federales y el de la Confederación continuó, y las hostilidades aumentaron en todos los estados de dominio liberal. En el Cauca, por ejemplo, los hechos siguieron una dinámica similar a la de Santander y hubo levantamientos conservadores contra el presidente de Mosquera quien gobernaba en alianza con los radicales. El caudillo caucano había tomado esa deriva después de perder las elecciones de 1856, en las que participó de modo independiente contra Ospina y contra Murillo Toro.

A comienzos de mayo de 1860, Mosquera declaró la separación del Cauca del gobierno de la Unión, y a su vez, la guerra al gobierno de Ospina. Otros estados liberales iban en la misma dirección, pues en abril Salgar había decretado un “crédito" por $\$ 80.000$, destinado al departamento administrativo de "Guerra" ${ }^{19}$, y en junio como presidente de Santander, junto a los del Magdalena y Bolívar, se declararon independientes de la Unión, en protesta por las leyes nacionales.

17 Aquileo Parra, Memorias de Aquileo Parra (Bucaramanga: Imprenta Departamental de Santander, 1990), 150.

18 Felipe Pérez, Anales de la Revolución (Bogotá: Imprenta del Estado, 1862), 291, 428.

19 El Departamento de Guerra contemplaba la asignación salarial a las siguientes áreas: fuerza pública, servicio postal, hospitales militares, movilización, vestuario, armamento, indemnizaciones por expropiaciones y defunciones. 
El 25 de junio Ospina declaró la guerra a Santander, y en la primera semana de julio sus tropas ingresaron a las provincias del sur del Estado. Las fuerzas de la Unión estaban organizadas en varias columnas: una estaba al mando del jefe conservador santandereano Régulo García Herreros, otra al mando del coronel Melchor Corena, jefe de la anterior revolución, quien había sido capturado en La Concepción, pero amnistiado volvía ahora sobre sus pasos; y la tercera, la principal, era dirigida por Ospina y el general Pedro Alcántara Herrán. En total, unos 4.000 soldados. La primera ciudad ocupada fue San Gil. Luego tomaron a Bucaramanga, obligando al gobierno en pleno a huir, derrotándolo luego, el 16 de agosto en la batalla del "Oratorio", acaecida cerca de la ciudad del Socorro.

El gobierno de la Unión capturó al presidente de Santander, Antonio M. Pradilla, y a casi todo el gobierno radical. Entre otros a Narciso Cadena, Luis Bernal, Felipe Zapata, Eustorgio y Januario Salgar, Foción Soto, el general venezolano José María Monagas, Rudecindo López, David Granados, Aquileo Parra junto a sus dos hermanos, en total cerca de 300 hombres. Un parte del general Herrán reconoció en las fuerzas del gobierno 123 muertos, entre ellos el Coronel Melchor Corena, otros tres oficiales y 119 soldados, así como 143 heridos; de los santandereanos señaló que hubo unas 150 bajas, entre muertos y heridos ${ }^{20}$. Las cifras de los caídos en las batallas resultaban altas, quizá por la precariedad de las armas: se iniciaban con trabucos pero pronto se libraban cuerpo a cuerpo con lanzas y machetes.

Antes de su derrota los santandereanos vencieron a una pequeña fuerza del gobierno central en una escaramuza ocurrida en Galán, población de la provincia de El Socorro, después de la cual se retiraron para evitar al grueso de la tropa de la Confederación. Un movimiento táctico, diría Aquileo Parra; pero Ospina dijo respecto de las continuas retiradas de los santandereanos, que la campaña militar se había convertido en una "cacería de zorras". Parra, en sus Memorias narró los detalles de esa batalla: se habrían enfrentado unos mil soldados por Santander contra unos tres mil del gobierno central, que además contaba con apoyo de unos mil guerrilleros conservadores. De su relato llama la atención la descripción del trato dispensado a los notables capturados por parte del gobierno de la Confederación: él y otros jefes liberales fueron alojados bajo vigilancia en una casita junto a varios heridos, donde los visitó el Secretario de Gobierno de la Confederación, Manuel Antonio Sanclemente, quien se presentó con un par de sirvientes, ricas bandejas y abundante comida, más dos botellas de Champagne, y que luego fueron benévolamente saludados por parte del general Herrán. Después, la plana principal del gobierno santandereano capturada fue trasladada a Bogotá, donde las condiciones no fueron tan buenas y debieron permanecer en prisión cerca de un año. A los soldados o "individuos de tropa”, como se los denominaba, una vez vencidos se les ofreció la prisión o la

20 Felipe Pérez, Anales de la Revolución, 416-418; Aquileo Parra, Memorias de Aquileo Parra, 168-175. 
incorporación a la fuerza vencedora por tres años. Obviamente escogieron lo segundo, pues era una práctica común en las guerras del siglo XIX ${ }^{21}$.

La incorporación de las "tropas” vencidas a los ejércitos triunfadores se facilitaba, pues muchos de los alistados eran campesinos arrastrados a las refriegas por parte de sus patrones y jefes políticos locales ${ }^{22}$. Se sabe que los líderes de las familias principales en cada localidad organizaban los batallones con sus parientes y peones, también con gente del común, pues muchos iban voluntariamente ${ }^{23}$. Quizá con las tendencias partidistas por localidad y los ataques entre poblaciones se cultivaron odios y se reforzó la identidad partidista, y la participación voluntaria; sin duda, que de esta salían los mandos intermedios, denominados comúnmente como "capitanes". Esto explica, en el caso santandereano, la persistencia de las guerrillas conservadoras que operaban principalmente en las provincias del norte. Tal era, por ejemplo, la guerrilla conocida como los "Gramalotes", de un pueblo con el mismo nombre. De estos se señalaba su dureza y crueldad en los combates; quizá por su carácter belicoso, cuando eran derrotados, sus adversarios les daban muerte sin contemplación, incluso degollándolos después de ser capturados, como se dijo que había sucedido en La Concepción, en la batalla donde Santos Gutiérrez y los Wilches vencieron a los conservadores. El dato aparece en una carta del general conservador Ramón Espina dirigida a Mosquera, en marzo 30 de 1859. Señalaba Espina que sabía poco de Santander, solo que Márquez iba en dirección del sitio donde se hallaban los que habían derrotado y dado muerte a Habacuc Franco, quien habría sido degollado junto a 90 de sus hombres después de capturados ${ }^{24}$. Así mismo, se dijo que en una batalla ocurrida en Bucaramanga, en junio de 1862, habían fusilado a muchos "gramalotes" después de su rendición ${ }^{25}$.

Cuando las fuerzas de la Confederación vencieron al gobierno de los liberales radicales, el general Leonardo Canal organizó por segunda vez una administración política de tinte conservador. Y el

21 Aquileo Parra, Memorias de Aquileo Parra, 176-177.

22 Juan Carlos Jurado Jurado, “Soldados, pobres y reclutas”, 211-235.

23 Respecto a las levas llevadas a cabo durante las guerras civiles, Álvaro Tirado Mejía, "Las relaciones entre la Iglesia y el Estado en Colombia”. Revista de la Universidad de Antioquia, 54, 210 (1987), 52-66. El reclutamiento forzado como práctica universal tendió a desaparecer con los procesos de profesionalización de los ejércitos. En las guerras civiles de Colombia del siglo XIX hay suficiente evidencia al respecto. No obstante, también la hay de la participación voluntaria por parte de campesinos, pequeños propietarios y artesanos, un aspecto poco investigado. A la participación voluntaria de los artesanos, hizo referencia el cura Pascual Afanador en La democrática de San Gil o Cartas del ciudadano José Pascual Afanador, dirijidas a los señores de la nobleza sanjileña, sobre la naturaleza i efectos de un programa (Socorro: Imprenta de N. Gómez i C. Villareal, 1851).

24 León Helguera y Robert Davis, Archivo Epistolar del General Mosquera. Correspondencia con el General Ramón Espina (Bogotá: Biblioteca de Historia Nacional, Kelly, 1966.), 294.

25 José Joaquín García, Crónicas de Bucaramanga (Bogotá: Banco de la República, 1982), 130-134. Según García, las fuerzas de Salgar fusilaron a los "Gramalotes" después de su rendición, y luego se ensañaron con sus cadáveres. La versión acerca de que numerosos prisioneros pasados por cuchillo en las diferentes batallas circuló poco, pero algunos autores hicieron eco de ello. Otero Muñoz, por ejemplo, minimizó el hecho para favorecer la imagen de Solón Wilches, mediante una versión según la cual él habría detenido la masacre por parte de sus fuerzas. Gustavo Otero Muñoz, Wilches y suépoca (Bucaramanga: Imprenta del Departamento, 1936). 
ocho de septiembre de 1860 se declaró gobernador mediante un decreto, que decía de sí mismo justificando su nuevo cargo: “[...] jefe que los pueblos han nombrado por aclamación”. Su gobierno operó en la ciudad de San Gil hasta diciembre, mes en el que trasladó la capital a Bucaramanga. En esta ciudad, de mayoría liberal, como de costumbre, aplicaron los consabidos empréstitos forzosos, embargaron suministros y establecieron multas a los liberales. Medidas represivas que se aplicaban unos y otros, cada vez que tomaban el control de ciudades y localidades.

Leonardo Canal no era ajeno a los problemas de la legitimidad, así que no solo se declaró "aclamado por el pueblo", sino que convocó una Constituyente de treinta y cinco miembros, todos conservadores, que se reunieron el diez de enero de 1861 y declararon abolida toda la legislación radical. Entre los constituyentes de ese año figuran los presbíteros N. Téllez y Francisco Romero, además del jefe conservador de San Gil Rito Antonio Martínez, quien presidió la Asamblea. Otros notables conservadores que conformaron el legislativo fueron: Guillermo Orbegozo, Eduardo Valencia, Crisanto Ordóñez, Arístides García Herreros, Cándido Navarro, Rafael María Rico, etc. La forma de organización política que se dispensaron no difiere en mucho de la que habían procurado los radicales: el presidente despachaba con dos Secretarías, la de Gobierno y la de Hacienda; se nombraron tres designados a la presidencia y se dividió el territorio en los mismos ocho departamentos, cada uno con un Prefecto (equiparable a los jefes departamentales), declarados "de libre remoción y nombramiento" por parte del gobernador; en cada distrito nombraron un alcalde y en las aldeas un comisario; igualmente designaron un Tribunal Supremo de tres miembros, jueces de circuito y jueces parroquiales, estos últimos elegidos por los jueces de circuito, quienes a su vez serían nombrados por los magistrados. Además declararon vigentes las leyes anteriores a 1856, mientras elaboraban las propias. García el autor de las crónicas aquí citadas, dijo de la Asamblea que "con raras excepciones, todos eran doctores y todos eran notables"26.

Desde comienzos de 1861 Ospina organizó las elecciones a la presidencia de la Confederación, a la vez que preparaba tropas para enfrentar las fuerzas de Mosquera que avanzaban desde el Cauca y se aproximaban a la capital. Como se podía esperar, las presidenciales fueron ganadas por el general conservador Julio Arboleda; pero no pudo posesionarse en marzo, como estaba previsto, porque los congresistas liberales no se presentaron y no hubo quórum. Ante tal circunstancia Ospina cedió la silla al Procurador Bartolomé Calvo el primero de abril de 1861. Su magistratura no superó los tres meses, pues Mosquera lo derrocó en el 18 de julio siguiente ${ }^{27}$. Cuando Mosquera tomó Bogotá puso en libertad a varios líderes radicales santandereanos que desde el “Oratorio” permanecían en prisión.

26 José Joaquín García, Crónicas de Bucaramanga, 121-122.

27 Felipe Pérez, Anales de la Revolución, 626. 
Quizá ese fue el encarcelamiento más largo que hayan pagado los notables del siglo XIX, pues no era la norma, la práctica más extendida era la de decretar amnistías o el destierro.

Una vez triunfó la revolución, los jefes liberales de los estados de Bolívar, Boyacá, Cauca, Cundinamarca, Magdalena, Tolima y Santander se reunieron el 9 de septiembre de 1861 y acordaron confederarse; además, reconocieron como presidente transitorio al general Mosquera ${ }^{28}$. Entre las primeras medidas que tomó estuvieron las dirigidas contra la Iglesia, en parte una represalia por su actuación abierta al lado de los conservadores; pero no se puede ignorar que frente a las acucias fiscales, Mosquera, como otros políticos, siempre fijaban sus ojos en la institución que presumiblemente tenía riqueza. El 20 de julio se publicó una ley que prohibía a los sacerdotes ejercer sin autorización del gobierno, medida conocida como "tuición de cultos”. Luego, el 26 del mismo mes se expropió y se expulsó a los jesuitas, y el 9 de septiembre se decretó la desamortización de bienes eclesiásticos ${ }^{29}$.

Mientras tanto en Santander, el general Salgar dirigió las fuerzas que recuperaron algunas de las ciudades de Santander que permanecían en poder de las guerrillas conservadoras. El primero de octubre de 1861 tomó la ciudad de Bucaramanga, erigida como capital, y procedió a las acostumbradas expropiaciones y represalias. Luego convocó la Asamblea de modo extraordinario, esta sesionó por 3 días y restauró los impuestos de aguardientes y de degüello de ganado, y organizó otra Constituyente para el siguiente año ${ }^{30}$. Sus planes se vieron interrumpidos porque en diciembre las fuerzas conservadoras del coronel Obdulio Estévez ${ }^{31}$ retomaron la ciudad, y Salgar se vio obligado a huir junto a su gabinete. Entonces el comerciante conservador Adolfo Harker -cuyas memorias se citan aquí - asumió como presidente del Estado. Salgar en su retirada llegó hasta El Socorro, desde donde procuró seguir gobernando a la vez que reorganizaba sus fuerzas. Lo primero que hizo en la capital comunera fue aplicar un "crédito" de \$218.912, para gastos de orden público. Se trataba de una cantidad significativa, pues representaba más de dos tercios del presupuesto de ese año ${ }^{32}$. Harker en Bucaramanga hizo lo propio: organizó el cobro de impuestos y aplicó un "crédito forzoso". "Crédito" era un eufemismo, pues la mayoría de las veces se trataba de expropiaciones e impuestos extras que nunca se devolvían a los “contribuyentes”. Podemos imaginar lo ruinosas que resultaban la guerras

28 Javier Díaz Díaz, "Del faccionalismo a la unidad liberal en el ocaso del federalismo, 1876 - 1877" (Tesis de pregrado, Escuela de Historia, Universidad Industrial de Santander, 1999), 98.

29 David Church Johnson, Santander siglo XX, 171.

30 David Church Johnson, Santander siglo XX, 171.

31 El coronel conservador Obdulio Estévez estuvo al frente de las fuerzas conservadoras que tomaron a Bucaramanga. Sus procedimientos escandalizaban a hombres como Adolfo Harker, que tenía ascendencia y educación inglesa. Él cuenta en sus memorias que en una oportunidad Estévez hizo colgar a un humilde hombre que se declaró remiso a su milicia, y anota que Estévez no gustaba de formar parte de ejército alguno, sino de operar en guerrillas. Harker manifiesta que no compartía su proceder, y recuerda que lo mataron en el atrio de iglesia, frente al patíbulo que él montó para colgar al labriego remiso.

32 Gaceta de Santander, 27 de mayo, 1862, 523-524; 19 de jun., 1862, 532; 26 de jun, 536 
para los vecinos de estas ciudades, por la sucesión de presidentes de una y otra facción, cuando no, bajo la circunstancia tan desgraciada aquí mencionada, de sufrir dos gobiernos simultáneamente.

Entre diciembre de 1861 y el 26 de agosto de 1862, Bucaramanga fue atacada por lo menos otras seis veces. Hasta agosto, que las fuerzas de Salgar lograron vencer a los últimos guerrilleros conservadores que habían tomado la capital una semana antes. Fue en esa retoma de la ciudad cuando, según la versión del cronista José Joaquín García, los capitanes de Salgar habrían fusilado a los rendidos y se habrían ensañado con los cadáveres. Algunas de las batallas libradas en las cabeceras denotan una inusitada violencia por parte de los lugareños, tal vez por las retaliaciones contra los vencidos, hombres venidos de otros pueblos que algunos días antes los expropiaban, que quizás habían matado a sus parientes, violado a sus mujeres, y ejecutado otros actos de barbarie que las crónicas describen. Como se dijo antes, los notables mantenían reglas de respeto ancladas en valores como "el honor", pero que no alcanzaba a los "individuos de tropa", ya fuesen obligados o voluntarios. De tal manera, cuando las circunstancias superaban a los notables ungidos como jefes, los del común actuaban con desenfreno.

\section{La Iglesia en la revolución}

Cuando los liberales civilistas llegaron al poder en marzo de 1849 con José Hilario López, se estableció que los curas serían elegidos por votación popular en los cabildos municipales de entre los candidatos propuestos por el diocesano. Ese mismo año se suprimieron los diezmos y se decretó la separación de la iglesia y el Estado; se estableció el matrimonio civil y el divorcio, se suprimió el fuero eclesiástico, se redimieron los censos y se expulsó a los jesuitas; luego en 1853 fue eliminada la renta del Estado asignada a los clérigos para su manutención, obligándolos a depender solo de las limosnas de los fieles. No obstante, con el triunfo electoral de los conservadores en 1856, encabezados por Mariano Ospina Rodríguez, la Iglesia recuperó sus posiciones. Pero temporalmente, pues todas las medidas contra la Iglesia fueron nuevamente impuestas en 1861 por el general Mosquera ${ }^{33}$. A lo largo de ese decenio los liberales aprobaron un conjunto de medidas que afectaban las esferas de poder político y control social del clero, tales como el matrimonio civil y la declaración de libertad de enseñanza. Todas las políticas que apartaban a la Iglesia del poder político fueron ratificadas por el Estado Federal de Santander en 1857, lo que explica en parte que en la guerra del sesenta los curas de la Diócesis San Pedro Apóstol de Pamplona tomaran las armas junto a los conservadores, igual hizo el clero de otros estados liberales.

33 Álvaro Tirado Mejía, “Las relaciones entre la Iglesia y el Estado en Colombia”, 52-66. 
La clerecía santandereana auguró lo peor cuando los liberales encabezados por Murillo Toro asumieron todo el poder en Santander a finales de 1857, pues entre ellos estaban los hombres que habían ejercido como ministros durante el gobierno de José Hilario López. Efectivamente, la constitución fundacional resultó liberal y laica. La resistencia del clero solo hizo que los radicales profundizaran sus medidas, así por ejemplo, en el "empréstito” de octubre de 1861, el presidente Salgar ordenó incluir en el listado de "contribuyentes" a todos los curas de Santander. Pero no todos podían ni querían pagar, y mediante diferentes excusas muchos lograban capear los pagos. Uno de estos casos lo ejemplificó Rudecindo Gómez, de la arquidiócesis del Socorro, quien mediante carta al Jefe departamental alegó que no tenía los $\$ 1.000$ que le exigían, pero que él no había sido hostil al gobierno y que estaba dedicado a "curar almas", que por lo tanto ofrecía servir durante un año como capellán y administrador del lazareto sin recibir pago alguno; también ofreció entregar al gobierno $\$ 300$ en recibos de empréstitos hechos al tesoro del Estado en 1859, es decir, recibos de otro empréstito forzoso, también decretado por Salgar ${ }^{34}$. Por esa carta y su manifiesta voluntad el gobierno lo eximió de la contribución. Pero no todos corrieron con la misma suerte, pues los liberales tuvieron presente su participación a lo largo de la guerra.

La actuación de los clérigos en la revolución conservadora fue evidente, pues cada vez que los liberales obtenían alguna victoria, entre los jefes capturados destacaba algún sacerdote. Así por ejemplo, el 20 de junio de 1862, en la población de Galán, tuvo lugar una de las últimas batallas de esa guerra, y entre los capturados figuraba el presbítero conservador Félix Torres, catalogado como el jefe de la guerrilla de Mogotes $^{35}$. Otra prueba de tal participación la obtuvieron los liberales en Pamplona, cuando incautaron en la casa de Francisca Peralta el archivo del líder conservador, general Leonardo Canal. Entonces se dijo que un documento, del obispo de la Diócesis de la ciudad, evidenciaba su participación y los acuerdos con los revolucionarios ${ }^{36}$.

Otro reconocido clérigo y líder de las guerrillas fue el cura Francisco Romero, quien comandaba unos 40 guerrilleros en Pamplona y en la frontera con Venezuela (Cúcuta y el Táchira), de esto dieron cuenta diferentes noticias a lo largo de $1859^{37}$. Otro ejemplo lo representa el sacerdote Andrés Blanco capturado en la batalla del 29 de agosto de 1859, acaecida en La Concepción, donde fue capturada

34 Gaceta de Santander, 3 de enero 1861, 513.

35 Gaceta de Santander, 27 de mayo, 1862, 526. En esta batalla también fue capturado Adolfo Harker, procurador del gobierno conservador y que como tal había asumido la presidencia del Estado, cedida a su vez por Leonardo Canal, quien al observar el avance de los liberales evadió la confrontación y avanzó con sus fuerzas hacia el sur del país; también fue capturado por tercera vez a Blas Hernández, tercer designado a la presidencia; igualmente, a Benjamín e Idelfonso Hurtado, jefes de la rebelión en Charalá; a Epaminondas Canal y Cristóbal García, calificados como “rebeldes consuetudinarios” en Soto; también a Vicente Ramírez, guerrillero de San Joaquín, entre otros.

36 Gaceta de Santander, 2 de octubre, 1862, 578.

37 Gaceta de Santander, 6 de julio, 1859, 334. 
la plana mayor conservadora, junto a los hermanos Canal y unos 300 de sus hombres ${ }^{38}$. Como se quiera, resultan numerosos los casos que mencionan a los presbíteros en armas.

Si bien muchos curas se vincularon a las guerrillas conservadoras, también hubo otros que no lo hicieron y se mantuvieron al margen; algunos de ellos eran afines a los radicales y obedecieron las disposiciones del gobierno, en contravía de lo orientado por su obispo. Se trataba de clérigos que ejercían en poblaciones con tradición liberal; esto se evidencia por sus apellidos, como los casos del presbítero de Bucaramanga José María Valenzuela, de Bernardo Olarte y Ramón Olarte, de Vélez ${ }^{39}$.

La expropiación y expulsión de los jesuitas, decretada por Mosquera en 1861, estuvo acompañada de una prohibición a todos los sacerdotes para hacer liturgias y demás actividades propias de su oficio. Para hacerlo deberían tramitar "un salvoconducto" que se lograba mediante una declaración de sometimiento al gobierno del Estado y al de la Unión. Muchos se acogieron a tal requisito, entre ellos varios que huyeron a Venezuela durante la guerra. Entre estos, el acaudalado Francisco de Paula Orbegozo, que antes de presentarse envió desde San Antonio del Táchira una carta al presidente del Estado indicando que él no se había involucrado en las hostilidades contra el gobierno, y que había estado dedicado a cumplir como ministro de la iglesia; además argüía que por su edad, "algo más de 70 años", solo esperaba "el descanso de la tumba", y que no consideraba necesario el salvoconducto, pero que se sometía a las leyes, y rogaba que se lo expidieran. Lo que efectivamente hizo el gobierno. Solicitaba que su sometimiento no implicara el indulto, ya que sencillamente quería ejercer como sacerdote $^{40}$.

Otro caso similar de sometimiento fue el del párroco Pedro Felipe Mantilla, quien se presentó el 14 de marzo de 1863 en la jefatura departamental de Cúcuta y mediante un documento juró que reconocía al gobierno de los Estados Unidos de Colombia, y que se sometía a los decretos de "tuición” y "desamortización de bienes de manos muertas" y demás disposiciones del gobierno nacional y del Estado; pero agregaba “[...] siempre que estas no se opongan como lo espero al dogma de la religión católica, apostólica y romana”. Además ofreció no hostilizar directa ni indirectamente a ninguno de los dos gobiernos, como lo exigía el decreto ${ }^{41}$. Algunos presbíteros en prisión también procedieron a declarar sometimiento al gobierno: en Ocaña el 21 de abril de 1863 lo hicieron, el antes mencionado Francisco Romero, Pío Ortega, y otro de apellido Villamizar; los tres habían sido capturados junto a guerrilleros conservadores ${ }^{42}$. Y así muchos otros que, involucrados o no, debieron jurar obediencia al gobierno liberal.

38 Gaceta de Santander, 13 de septiembre, 1859, 359-360.

39 Gaceta de Santander, 25 de junio, 1862, 107; 9 de julio, 1862, 133; 16 de julio, 1862, 137.

40 Gaceta de Santander, 26 de marzo, 1863, 49.

41 Gaceta de Santander, 2 de abril, 1863, 54.

42 Gaceta de Santander, 7 de mayo, 1863, 73. 
El obispo de Pamplona, José Luis Niño, desde su destierro en El Táchira y mediante una circular del 10 de agosto de 1861, hizo saber a sus subalternos que no debían someterse al gobierno "ni autoridad humana alguna, aun si tuviesen que sufrir el destierro y la muerte”, y les advertía, que en caso contrario serían suspendidos de sus funciones ipso facto. Pero la mayoría le desobedeció, aun los más recalcitrantes, como Ortega, Romero y Villamizar; si bien lo hicieron después de pasar alrededor de dos años en prisión, tal como lo recordaban en su declaración de sometimiento. De esto también daba cuenta una carta que envió Ortega al Obispo, explicando su decisión y la de sus colegas en prisión. Señalaba que lo habían hecho porque ya la mayoría había procedido en tal sentido, incluso los que estaban en libertad, y mencionaba a los curas Francisco Orbegozo y Felipe Mantilla, de los que agregaba que se encontraban en San Antonio del Táchira "gozando de libertad y muy ricos".

\section{La Guerra de 1876}

“La guerra de 1876", también recordada como "La revolución conservadora de 1876” o "La guerra de los curas", se inició en el Cauca en el mes de julio; luego se extendió por Antioquia, Tolima y Cundinamarca. Unos meses más tarde y con menor intensidad, por Boyacá y Santander. El antecedente inmediato estuvo en las elecciones a la presidencia de la Unión disputadas por Aquileo Parra y Rafael Núñez, con incidentes graves en algunos estados, entre ellos Bolívar ${ }^{43}$. Pero no fueron las facciones liberales enfrentadas en campaña las que libraron la guerra posterior, sino las dos facciones unidas contra los conservadores, que por su parte, nuevamente actuaron en alianza con la Iglesia católica. Entre las causas de la confrontación, los estudiosos del tema, señalan la Ley de inspección de cultos votada en el Congreso de la Unión ${ }^{44}$. Pero algunos conservadores contemporáneos, como el sangileño Carlos Martínez Silva argumentaron que se decidieron por la guerra porque no se les reconocía el derecho al sufragio.

La confrontación comenzó animada por los obispos de Pasto y Popayán, según hechos descritos en los comunicados del gobernador del Cauca, César Conto, publicados en las gacetas oficiales de los estados. Otro tanto ocurría en el conservador Estado de Antioquia, donde sus obispos emitieron pastorales contra el gobierno de la Unión, con apoyo del gobierno estatal. ¿Qué alegaban los obis-

43 Varios incidentes de mediados de 1875 presagiaron la guerra. Hubo un ataque de fuerzas del Estado de Bolivar a sus similares de la Unión, por esto el Presidente Santiago Pérez alistó 3.000 hombres, que luego elevó a 10.000, a los cuales Santander aportó 700. 44 Memoria del Secretario de lo Interior i Relaciones Exteriores de los EE. UU. de Colombia al Congreso de 1877 (Bogotá: Imprenta de Rafael Pérez, 1877), 43-44. La Ley de inspección de Cultos, según Carlos Nicolás Rodríguez, se hizo para "[...] para afirmar la libertad de conciencia" - como era evocada la religión por parte de los radicales-; afirmaba que se buscaba dar "[...] protección al culto dominante, pero defendiendo la autoridad civil contra las usurpaciones de soberanía de la autoridad eclesiástica"; igualmente que se buscaba "[...] impedir que el clero abusase de la ignorancia de la multitud imponiendo gravámenes indebidos [...] La religión es santa, pero el sacerdote es hombre, tiene las pasiones de su especie i naturalmente la propensión a abusar de su poder. Además, todo poder tiende a ensancharse, i si en esa tendencia no encuentra ningún obstáculo, llega hasta la absorción de los demás". 
pos? Sus comunicados condenaban la Constitución de Rionegro, la libertad de cultos, "los gobiernos ateos", las escuelas laicas y la persecución a los clérigos ${ }^{45}$. Todo ello formaba parte de las causas expuestas en la guerra de 1860: se trataba, por una parte, de la lucha de la Iglesia por mantener su cuota de soberanía en el Estado, y por otra, de los radicales que procuraban marginar el clero de las decisiones políticas; igualmente, los conservadores reclamaban un sistema electoral que les permitiese una mayor representación en el gobierno.

Cuando la revolución conservadora estalló en el Cauca a finales del mes de julio, el presidente Parra elevó la fuerza de la Unión a 3.445 y luego, el 16 de agosto, declaró turbado el orden público y decretó el alistamiento de 20.000 hombres. El 23 de ese mismo mes, después de un nutrido intercambio de correspondencia con los jefes liberales de Santander, Parra nombró a Solón Wilches jefe de los batallones de Santander ${ }^{46}$. Estos eran contradictores políticos, pues Parra lideraba la facción radical y Wilches la Independiente, pero el segundo tenía ascendente entre los jefes militares que habían triunfado en la guerra de 1860. La alianza resultaba inevitable para los radicales, ya que de otro modo, el caudillo militar de Santander se habría decantado por el bando conservador, de quienes recibió varias cartas animándole a sumar fuerzas.

Wilches estuvo durante dos meses y medio alistando una fuerza, que finalmente quedó compuesta por dos divisiones y una columna: la Primera División, integrada por fuerzas del Socorro, Vélez y Guanentá, al mando del general Ramón Rueda Martínez y del coronel Ricardo Obregón Arauz; la Segunda División conformada por fuerzas de Soto, García Rovira, Pamplona y Cúcuta, comandada por el general Fortunato Bernal, los coroneles José María Ruiz, Salvador Vargas y Joaquín Wilches; la columna de Ocaña quedó al mando de David Granados y Antonio Noriega Zúñiga. En su mayoría eran parientes de Solón Wilches, otros fueron sus socios en negocios como Vargas y, en general, miembros del clan de García Rovira, quienes además ocupaban cargos en el gobierno del Estado ${ }^{47}$.

El primero de agosto el ejecutivo de la Unión envió una división de la Guardia colombiana al Cauca. El ocho de agosto el gobierno de Antioquia declaró el Estado en situación de guerra. Y el día 13 del mismo mes lo hizo el general Joaquín M. Córdoba, presidente del Estado del Tolima, quien asumió el mando de los rebeldes en Cartago y lanzó una proclama de guerra. A la misma respondió Parra con el citado alistamiento de hombres, cuyas columnas fueron aportadas por los estados de Cundinamarca, Santander, Magdalena, Bolívar y Panamá. El 31 de agosto, los revolucionarios sufrieron una primera derrota en la batalla de los Chancos, quizá la principal de esta guerra, en la que Julián Trujillo emergió

\footnotetext{
45 Memoria del Secretario de lo Interior, 16

46 Memoria del Secretario de lo Interior, 16.

47 Nectalí Ariza Ariza. “Los Wilches Calderón: red familiar y poder político en el Estado de Santander 1857-1886". Anuario Colombiano de Historia Social y de la Cultura 41: 2 (2014): 23 - 64.
} 
como el principal caudillo del ejército de la Unión. Se dijo que los revolucionarios sumaban unos 6.000 hombres $^{48}$.

Posteriormente, entre enero y febrero de 1877 sucedieron las batallas de Santander, las de Mutiscua y La Donjuana. La última confrontación significativa ocurrió en Manizales, el 5 de abril siguiente, y también fue liderada por el general Julián Trujillo. Después de esa batalla se rindió el general Silverio Arango, presidente de Antioquia y jefe principal de los conservadores. Trujillo quedó así como el general laureado de la contienda y con el camino abierto a la presidencia de la Unión, que ocupó un año después.

Tanto en el escenario del sur, del occidente y del norte, las acciones que definieron la guerra sucedieron relativamente pronto. Las batallas del Cauca, Antioquia y Tolima, se llevaron a cabo entre junio y agosto, mientras que en Santander se llevaron a cabo entre septiembre de 1876 y mayo de 1877. Tiempos breves si los comparamos con los hechos de la guerra iniciada en 1859, que tuvo diferentes episodios hasta 1862.

Entre los jefes conservadores de Santander alzados en armas figuran algunos comandantes revolucionarios que también lo habían sido en la revolución de 1860. De ellos los principales fueron los hermanos Canal; Eusebio Mendoza, Aquilino Gómez y otros. En ese conjunto de jefes destacaron: Guillermo Quintero Calderón, González de la Cruz, Carlos Martínez Silva, Manuel Briceño, Alejandro Posada, Lázaro María Pérez, José María Samper, Antonio y Juan N., Valderrama, José Domingo Ospina, Sebastián Ospina, Manuel Silva Baños, Víctor Cardoso, Ricardo Martínez Silva, Guillermo C. Jones, Leónidas S. Navas y el coronel Obdulio Estévez, entre otros ${ }^{49}$.

Antes de que ocurriesen las batallas decisivas de Mutiscua y de La Donjuana, los conservadores alcanzaron a tomar las ciudades de Bucaramanga, Pamplona, y varias poblaciones. Como antes, organizaron un gobierno provisional, al frente del cual pusieron a José María Samper, a quien ungieron como presidente del Estado de Santander; igualmente en la Unión nombraron a Alejandro Posada.

Después de la guerra se votó la Ley 35 de 1877 sobre inspección civil en materia de cultos, que permitió apresar a varios clérigos involucrados, entre ellos el de Bucaramanga. En todo el país los obispos, instigadores claros de la feligresía, fueron desterrados: de Pasto, de Popayán, de Medellín y Pamplona. El de esta última ciudad, Ignacio Antonio Parra, pudo regresar durante el gobierno de Wilches (1878-1880) en virtud de mediación que hiciera Camacho Roldán y también porque desde 1880 en Santander, los independientes establecieron alianza con los conservadores.

48 Memoria del Secretario de lo Interior, 24-26.

49 Manuel Briceño, La Revolución (1876-1877), Recuerdos para la Historia, (Segunda edición). (Bogotá: Imprenta Nacional, 1947) 423 . 
Si bien la guerra se definió en un par de batallas, hubo un sinnúmero de escaramuzas y pequeñas contiendas con la violencia acostumbrada. La guerra terminó con la derrota de los conservadores y los acostumbrados acuerdos de paz. En uno de estos pactos, firmado entre el coronel Ricardo Obregón y los comisionados del jefe rebelde general Antonio Valderrama, este se comprometió a “[...] entregar los elementos de guerra [...] excluyéndose las espadas y pistolas de los jefes y oficiales [...] a no tomar armas en contra del gobierno nacional ni de ninguno de los estados". Por su parte, los gobiernos de la Unión y de Santander se comprometieron a dar garantías y seguridad a los rendidos; al efecto se les expidió salvoconductos a los jefes y oficiales ${ }^{50}$.

Respecto al número de muertos y heridos en las batallas decisivas de Santander se dijo que habían sido mayores las bajas de la batalla de La Donjuana. En total hubo unos 750 muertos y 980 heridos, entre liberales y conservadores ${ }^{51}$. Si a esa cifra sumamos los de Mutiscua y los de las múltiples refriegas, se infiere que las bajas pudieron superar los mil hombres.

Cuando se firmó la paz, muchas guerrillas locales procedieron a rendirse. Los informes muestran que muchos se alistaban sencillamente para defenderse de sus vecinos, como lo señalaba un jefe gobiernista desde Guaca:

[...] inmediatamente llegué se me presentó Simón Manosalva y me entregó cinco armas que era lo único que tenía a su cargo. Ahora mismo se va para el páramo a hacer que venga el resto de los guerrilleros a presentarse. Esta pobre gente, no son, ni han sido nunca godos, [...] las miserables rivalidades lugareñas los obliga a buscarle el lado contrario a Miguel Vásquez, a los Sepúlveda $[. . .]^{52}$

De la guerra de 1876 quedaron relatos de crueldad, violencia excesiva e injustificada, como los que trascendieron del asalto a la población de El Carmen en Santander, llevado a cabo por el general conservador Guillermo Quintero Calderón a mediados de junio de 1877. Sus hombres saquearon las casas y violaron a las mujeres que permanecían en la población, dieron muerte a varios vecinos e incendiaron sus casas. Todo ello mientras daban vivas a la religión católica, al ejército regenerador y al partido conservador, según un testigo ${ }^{53}$.

50 Archivo de Solón Wilches (ASW), “Acuerdo de paz”. San Andrés, smd, caja 14

51 Manuel Briceño, La Revolución, 423.

52 A.S.W., "Natividad a S. Wilches", Guaca a San Andrés, 26 de febrero, 1877, c. 14.

53 “Documentos Históricos relativos a la Guerra. 1876-1877”, 18 de junio, 1879. 


\section{El ocaso del liberalismo radical: la Guerra de 1885}

Esta guerra tuvo en Santander una serie de hechos militares, semejantes a los acaecidos en las dos anteriores, como si se tratase de un guion a cumplir en cada conflicto. Comenzó por el asalto y la toma de pequeñas localidades y luego de las ciudades, por parte de las guerrillas conservadoras del norte.

El antecedente inmediato fueron las elecciones a la presidencia de Santander de mediados de 1884. Solón Wilches el presidente saliente que llevaba seis años sentado en la silla presidencial, intentó imponer a su aliado Francisco Ordóñez, en contra del presidente de la Unión, Rafael Núñez, quien quiso imponer un candidato propio; los radicales, por su parte, compitieron con Eustorgio Salgar. El triunfo de Ordóñez fue calificado de fraudulento por los radicales y por los conservadores que se levantaron en armas. Núñez intervino con tropas y con el envío de dos plenipotenciarios a dialogar con las partes: Felipe Zapata y Francisco Lineros, un radical y un independiente, respectivamente. Todos firmaron un pacto de paz y convocaron elecciones para una convención que denominaron "popular"; mientras tanto Lineros se hizo cargo de la presidencia. En la justa electoral a la Convención vencieron los radicales, pero los conservadores e independientes ignoraron los acuerdos para mantener a Lineros en la presidencia, y los radicales decidieron ir a la guerra ${ }^{54}$.

$\mathrm{Al}$ inicio de las sesiones de la Convención popular se supo que las guerrillas conservadoras de Silos, Gramalote y Arboledas, bajo el mando de un tal Rojas, avanzaban hacia las ciudades del Norte. En el mes de noviembre ya ocupaban San José de Cúcuta, pero fueron desalojadas en diciembre por las tropas del general Daniel Hernández. En enero de 1885, tanto en el norte como en otras localidades había escaramuzas por doquier. Dado el acuerdo hecho entre Núñez y los conservadores, las noticias en los diarios oficiales se invirtieron en la forma respecto a las guerras anteriores: las guerrillas y ejércitos rebeldes eran los radicales, mientras que los conservadores y antiguos guerrilleros eran el Ejército de la Unión. Sus partes victoriosos representaban lo mejor de las noticias, mientras que a los radicales se los trataba de "rebeldes", "bandoleros", "hombres que delinquen", etc. ${ }^{55}$. Esto se explica porque en esta guerra las guerrillas conservadoras que durante los decenios anteriores habían fustigado a los radicales pasaron a formar parte del ejército de la Unión. Los batallones tomaron los nombres de algunas de esas guerrillas en correspondencia a sus pueblos de origen: "Batallón Gramalotes", por ejemplo.

Antes, a finales de 1884, los radicales alistaron hombres en armas en Soto, Cúcuta, García Rovira, Vélez y El Socorro. Una de las fuerzas más significativas era dirigida por Daniel Hernández, encarga-

54 Julio Palacio H., La guerra de 1885, 22-23.

55 Gaceta de Santander, 13 de enero, 1885, 1745. 
do de la jefatura de las fuerzas revolucionarias asimiladas en el gobierno de transición resultante del pacto de paz. Pero cuando se desconocieron las decisiones de la Convención Popular el general se alió con los radicales y avanzó hacia el norte y recuperó la ciudad de Cúcuta del dominio de las guerrillas conservadoras de Gramalote y Arboledas. Esta información fue consignada en una carta que desde Bucaramanga le envió Juan Manuel Dávila al presidente Solón Wilches el 28 de noviembre. En la misma se lamentaba de que la Guardia colombiana no actuara en ninguna parte porque tenían la orden de no moverse. Núñez negociaba entonces las alianzas más convenientes para enfrentar a los radicales, a la vez que arrancaba concesiones a Wilches; además, entregó la jefatura de las fuerzas oficiales del norte a los generales conservadores Leonardo Canal y Guillermo Quintero Calderón, quienes desde la guerra de 1860 luchaban contra el gobierno liberal.

Un segundo acto de ese conflicto, que parece calcado de la guerra de 1876, fue el llamado a Wilches para que asumiese el mando del ejército de Santander el 27 de enero de 1885; pero en esta oportunidad fue Núñez quien lo nombró, a su pesar, pues se tenían mutua desconfianza, pero Núñez no tenía margen para otra decisión, pues el general santandereano comandaba cerca de mil hombres, quizá los mejor armados en la época ${ }^{56}$; así que se trataba de protocolizar un hecho y garantizar que se mantuviese a su lado. Por la correspondencia se infiere que Núñez temió hasta último momento que Wilches diese un bandazo y se aliase con los radicales. Pero no ocurrió tal cosa, el santandereano mantuvo la jefatura militar hasta el mes de julio, cuando se consideró que la guerra estaba superada después de la batalla de La Humareda, acaecida el 17 de junio de ese año.

Otras prácticas de esta guerra, también ejecutadas en las anteriores, fueron los actos de barbarie, expropiaciones y empréstitos realizados después de ocupadas las ciudades. También los largos desplazamientos que llevaron a cabo los revolucionarios: desde el sur al norte de Santander, del norte hasta los límites con Boyacá, desde allí hasta los puertos del Magdalena, donde tomaron vapores hacia la costa, región en la que parecía consensuado que se decidiría el triunfo o la derrota ${ }^{57}$. Esto último sí que parece nuevo, pues en 1861 y 1876 el control de las capitales de los estados decidía estratégicamente el triunfo, y en 1885 esto lo definió el control del Río Magdalena; fue en su cauce y entorno donde se desarrollaron las batallas decisivas. Otro detalle de estas confrontaciones en el que poco se repara, es que estuvieron "aderezadas" con epidemias de viruela y sarampión, que se extendieron por varias poblaciones. Las noticias y las cartas dieron cuenta de su presencia entre las fuerzas de unos y

56 Wilches, en sus últimos seis años de presidencia en Santander, dedicó buena parte del presupuesto a comprar armamento en New York.

57 Gonzalo España, Laguerra de 1885. 
otros. En una carta de José María Camargo a Wilches le informaba acerca de los estragos causados de tales enfermedades en la fuerza de Bucaramanga ${ }^{58}$.

De las batallas, las más memorables fueron la de Cartagena y La Humareda ${ }^{59}$. En esta última murieron varios generales radicales, entre ellos, Fortunato Bernal, general emparentado con el presidente Solón Wilches, pero que entonces, junto a otros miembros de la familia y de aliados de la provincia de García Rovira luchaban en el bando radical contra su antiguo aliado y contra las tropas de Núñez.

Con la guerra y la rendición de los líderes radicales, les sobrevino la cárcel y el destierro. Entre otros fueron obligados a partir Aquileo Parra y Foción Soto. El nuevo poder político en Santander fue encabezado por los conservadores y liberales independientes aliados con Núñez. Antonio Roldán fue nombrado Jefe Civil y Militar del Estado, y en la jefatura departamental de Soto fue nombrado el comerciante conservador Adolfo Harker, de quien dijimos antes, que encabezó en Girón el primer levantamiento armado de 1859.

Núñez convocó un consejo nacional para reformar la Constitución de 1863, con dos delegados por Estado, uno conservador y uno independiente. Por Santander acudieron Antonio Roldán, liberal independiente, y el general conservador José Santos. Se reunieron el 11 de noviembre de 1885 y el 30 se creó un gobierno provisional, compuesto por el presidente Núñez, como vicepresidente el general Eliseo Payán y como primer designado el general José María Campo Serrano, quien asumió la jefatura el 1 de abril de 1886. La Constitución fue sancionada el 5 de agosto. Por Santander firmaron la nueva constitución, en reemplazo de Roldán y Santos, el general Guillermo Quintero Calderón y Antonio Carreño. En esa fecha Roldán había pasado a ser Ministro de Hacienda y estaba encargado del ministerio de Guerra ${ }^{60}$.

\section{Conclusiones}

En los hechos reseñados, se observan la actuación de varios jefes políticos en las tres guerras. Este aspecto, además de imprimir continuidad a un conflicto durante décadas, invita a profundizar en las causas, como en los intereses que unos y otros defendían. En cuanto a las prácticas políticas,

58 A.S.W., José María Camargo a Solón, Bucaramanga, 20 de abril, 1885.

59 El 17 de junio ocurrió la batalla conocida como La humareda: El general Sergio Camargo atacó a Calderón con unos 2.000 hombres y 6 vapores. El enfrentamiento duró desde las 9 de la mañana hasta el anochecer. Ocurrió en un punto cercano al Banco (Magdalena), y si bien triunfaron los revolucionarios, fue un triunfo pírrico, pues murieron muchos rebeldes y 6 generales, tres de ellos santandereanos: Daniel Hernández, Fortunato Bernal, Plutarco Vargas, Pedro J. Sarmiento, Capitolino Obando y Bernardino Lombana. Fortunato y demás jefes radicales murieron al parecer "por accidente", al incendiarse uno de los vapores, que iba cargado de pólvora. Gonzalo España, La guerra de 1885; Foción Soto, Memorias sobre el movimiento de resistencia a la dictadura de Rafael Núñez, 1884 - 1885, Tomo 1 (Bogotá, Editorial Incunables, 1986).

60 Julio Palacio H., La guerra de 1885, 364, 387, 390. 
los partidos y sus facciones, utilizaron marcos normativos, pero en la misma medida o más, incurrieron en la ilegitimidad y la violencia. Esta es una cuestión conocida, aunque pocas veces detallada. Al respecto, las fuentes suelen referenciar continuamente el fraude, el ataque a las urnas; en las batallas aquí recordadas, se mencionan degollamientos y fusilamientos de los rendidos. No resulta difícil imaginar que en un tiempo en el que no existía un derecho establecido para los conflictos internos y donde los países regulaban las guerras en valores como el honor y en el derecho de gentes, la trasgresión a las normas básicas del humanismo, debió ser moneda corriente. Entre las prácticas políticas, igualmente puede observarse, el abuso de poder, con las expropiaciones y los impuestos abusivos, denominados entonces "empréstitos forzosos", que las facciones aplicaban a los vencidos, cuando no, al conjunto de la población.

Los actores colectivos como individuales en estas guerras, se traslapan, y los actores suplantaban la institucionalidad, así por ejemplo, los curas y obispos hicieron la guerra en nombre de la Iglesia; los presidentes de los estados en nombre de la legitimidad, del pueblo, y de la República; esto cuando realmente estaban defendiendo sus parcelas de poder, que compartían con miembros de sus facciones. Ahora bien, no escapa que en las contiendas y en el proceso político dado durante el federalismo, hubo actores cuya presencia traspasaba el ámbito de los gobiernos de los estados, como fueron la Iglesia católica y los partidos a los que bien podríamos calificar como actores del orden nacional con fuertes anclajes regionales a través de las familias notables en cada región, por esto quizá resulte pertinente profundizar en el estudio de estas y su participación en la política. La actuación de las familias y redes de notables provinciales en la historia política del país cuenta con pocos estudios, con excepción de unas cuantas dominantes. Se sabe que actuaban en cada Estado entrelazadas con muchas otras, en entramados relacionales donde compartían parentesco, cargos, negocios, contratos, filiación política y variadas prácticas de sociabilidad, tal es el caso de la red que en Santander se configuró en torno a la familia liberal de los Wilches Calderón ${ }^{61}$. Una de las familias que participaron de manera contundente en las tres guerras aquí reseñadas. La otra familia que participó de modo decisorio en las tres guerras, fueron los hermanos Canal González, cuatro hacendados de Pamplona, católicos furibundos que lideraron este partido en la región norte santandereana; dos de ellos estuvieron como constituyentes en 1857, y en las guerras fueron los comandantes de las fuerzas conservadoras, a la par estuvieron por poco tiempo al frente de gobiernos temporales, y de modo definitivo después de 1885. También los hermanos García Herreros, también del norte, figuraron entre los constituyentes conservadores que fundaron el Estado en 1857, pero lideraron la revolución y participaron en las batallas y en los sucesivos gobiernos que su partido logró. Igual sucede con los hermanos Orbegozo, los

61 Nectalí Ariza Ariza. “Los Wilches Calderón”, 35-45. 
hermanos Fructuoso y Salustiano Ortiz, etc. Estos últimos, igualmente tuvieron representación en la Constituyente fundacional del Estado y se vincularon a la guerra cuando los radicales alcanzaron la mayoría y excluyeron a los conservadores de los cargos en las localidades. Llama la atención de los Orbegozo, como de los Ortiz, que unos y otros, tuviesen respectivamente un miembro en la Iglesia, y otro como diputado en la Asamblea. Los curas participaron como asambleístas y como jefes rebeldes, principalmente en la primera y segunda de las guerras reseñadas. De otra parte, puede afirmarse que los jefes facciosos en general, participaron en los procesos electorales, en las constituyentes, como en las conflagraciones, y en estas, según los documentos, implementaron prácticas propias de ejércitos regulares, como de guerrillas.

¿Qué intereses tenían estos actores políticos en las provincias y en el Estado? Sin duda querían mantener o alcanzar cargos decisorios. Algunos autores han llamado la atención al respecto ${ }^{62}$ y es conocido que, en otras latitudes en los procesos de formación estatal modernos, los cargos lo eran todo; una realidad heredada de la colonia que tuvo continuidad en la República, incluso los funcionarios de los gobiernos durante el siglo XIX resultaban ser descendientes de cabildantes de la época colonial.

En Santander durante el periodo federal, tanto los liberales como los conservadores buscaban alcanzar la mayoría en la Asamblea, pues desde esta controlaban los nombramientos en las localidades, también el presupuesto y el recaudo fiscal, mediante el acaparamiento de los remates de aguardientes, de degüello de ganado, etc., igualmente, lo diputados decidían los nombres en las listas de contribuyentes al impuesto único a la riqueza. Los asambleístas asimismo incidían en los contratos de caminos y de los incipientes ferrocarriles, que entonces representaban las principales obras de infraestructura del país. El control del aparato del Estado, permitía el acceso a negocios comerciales y agrícolas que durante esos años se llevaban a cabo, como fueron las quinas y el café. Cabe recordar que en Santander desde el año 1870 surgieron los primeros bancos, y que en las últimas décadas del siglo XIX, Santander fue el primer exportador de café.

Las guerras civiles del Siglo XIX aquí reseñadas, junto a la de los Mil días, mantienen cierta continuidad respecto a las causas, intereses y forma en que se libraron, pues las mismas tuvieron como actores centrales a los partidos políticos, cuya expresión organizacional en el contexto de los estados, regiones y localidades resultaba esencialmente facciosa. Es conocido que varios jefes políticos, tanto del bando conservador como liberal, participaron activamente en las contiendas de finales de siglo. Quizá deba hablarse en singular: la Guerra civil de la segunda mitad del siglo XIX.

62 Consúltese, entre otros, a: Helen Delpar. Rojos contra azules, el Partido Liberal en la política colombiana, 1863-1899 (Bogotá: Tercer Mundo Editores, 1994); Teresa Uribe de Hincapié y Liliana María López Lopera, La guerra por las soberanías, 42. 


\section{Referencias bibliográficas}

\section{Fuentes primarias/documentales \\ Fuentes manuscritas:}

"Acuerdo de paz", en Archivo de Solón Wilches (ASW), San Andrés, smd, caja 14.

Archivo Histórico Regional de Santander (AHRS)

Archivo General de la Nación (AGN)

Biblioteca Luis Ángel Arango, Raros y curiosos (BLAA)

\section{Fuentes impresas}

\section{Publicaciones periódicas:}

Gaceta de Santander, Bucaramanga, 1858-1884.

\section{Libros}

Afanador, Pascual. La democrática de San Gil o Cartas del ciudadano JoséPascual Afanador, dirijidas a los señores de la nobleza sanjileña, sobre la naturaleza i efectos de un programa. Socorro: Imprenta de N. Gómez i C. Villareal, 1851.

Memoria del Secretario de lo Interior i Relaciones Exteriores de los EE. UU. de Colombia al Congreso de 1877,(1877) (2da edición), Bogotá: Imprenta de Rafael Pérez 1877.

Briceño, Manuel, La Revolución (1876-1877), Recuerdos para la Historia, Bogotá: Imprenta Nacional, 1947.

García, José Joaquín, Crónicas de Bucaramangaa. Bogotá: Banco de la República, 1982.

Harker, Adolfo, Mis recuerdos. Bucaramanga: Academia de Historia de Santander, 1954.

Palacio, Julio, La guerra de 1885. Bogotá: Editorial Cromos, 1936.

Pérez, Felipe, Anales de la Revolución. Bogotá: Imprenta del Estado, 1862.

Parra, Aquileo. Memorias de Aquileo Parra. Bucaramanga: Imprenta Departamental de Santander, 1990.

\section{Bibliografía consultada}

Ángel Correa, Ana Patricia, "Actores y formas de participación en la guerra vistos a través de la literatura", Ganarse el cielo defendiendo la religión. Guerras civiles en Colombia, 1840-1902, editado por Luis Javier Ortiz. Bogotá: Universidad Nacional de Colombia, 2005, 445-461.

Arango de Restrepo, Gloria, "Las mujeres, la política y la guerra vistas a través de la Asociación del Sagrado Corazón de Jesús. Antioquia, 1870-1885". En Ganarse el cielo defendiendo la religión. Guerras civiles en Colombia, 1840-1902, ed. Luis Javier Ortiz. Bogotá: Universidad Nacional de Colombia, 2005, 357- 444

Ariza Ariza, Nectalí. "Los Wilches Calderón: red familiar y poder político en el Estado de Santander 1857-1886". Anuario Colombiano de Historia Social y de la Cultura 41: 2 (2014): 23 - 64. DOI: http:// dx.doi.org/10.15446/achsc.v41n2.48781

Ceballos Gómez, Diana Luz, "La guerra de los Mil Días vista a través de las memorias". En Ganarse el cielo defendiendo la religión. Guerras civiles en Colombia, 1840-1902, ed. Luis Javier Ortiz. Bogotá: Universidad Nacional de Colombia, 2005, 62-95 
Deas, Malcolm. "Pobreza, guerra civil y política: Ricardo Gaitán Obeso y su campaña en el río Magdalena en Colombia, 1885”. En Del poder y la Gramática. Bogotá: Tercer Mundo Editores, 1993, 121-173.

Delpar, Helen. Rojos contra azules, el Partido Liberal en la política colombiana, 1863-1899. Bogotá: Tercer Mundo Editores, 1994.

Díaz, Javier, "Del fraccionalismo liberal en el ocaso del federalismo: La guerra civil de 1876-1877”. Tesis de pregrado en Historia, Universidad Industrial de Santander, Bucaramanga, 1999.

Echeverri Álvarez, Juan Carlos, “La guerra de 1885 en Colombia ¿̨crónica de un suicidio anunciado?”, Revista de Historia y Ciencias Sociales, No 16 (2009), 67-81.

Escobar Guzmán, Brenda, “La guerra de los Mil Días vista a través de las memorias”. En Ganarse el cielo defendiendo la religión. Guerras civiles en Colombia, 1840-1902, ed. Luis Javier Ortiz. Bogotá: Universidad Nacional de Colombia, 2005, 465-480.

España, Gonzalo, La guerra de 1885, Núñez y la derrota del radicalismo. Bogotá: El Ancora Editores, 1985. España, Gonzalo, Arbey Atehortúa y Mario Palencia Mario. Narrativa de las gouerras civiles colombianas. Bucaramanga: Ediciones Universidad Industrial de Santander, 2003.

Harker, Adolfo, Mis recuerdos. Bucaramanga: Academia de Historia de Santander, 1954.

Helguera, J. León y Robert Davis. Archivo Epistolar del General Mosquera, Correspondencia con el General Ramón Espina, Bogotá: Biblioteca de Historia Nacional, Kelly, 1966.

Johnson, David Church, Santander Siglo XX. Cambios socioeconómicos. Bogotá: Carlos Valencia Editores, 1984.

Jurado Jurado, Juan Carlos, “Soldados, pobres y reclutas en las guerras civiles colombianas”. En Ganarse el cielo defendiendo la religión. Guerras civiles en Colombia, 1840-1902, ed. Luis Javier Ortiz. Bogotá: Universidad Nacional de Colombia, 2005, 465-480

Ortiz, Luis Javier. Ganarse el cielo defendiendo la religión. Guerras civiles en Colombia, 1840- 1902. Medellín: Unibiblos, 2005.

Ortiz, Luis Javier. Obispos, Clérigos y fieles en pie de guerra: Antioquia, 1870-1880. Medellín: Editorial Universidad de Antioquia, 2010.

Otero Muñoz, Gustavo.Wilches y su época. Bucaramanga: Imprenta del Departamento, 1936.

Soto, Foción,Memorias sobre el movimiento de resistencia a la dictadura de Rafael Núñez, 1884 - 1885, T. 1. Bogotá: Editorial Incunables, 1986.

Uribe de Hincapié, Teresa y Liliana María López Lopera, La guerra por las soberanías. Memorias y relatos de la guerra civil de 1859-1862 en Colombia. Medellín: La Carreta Editores, 2008.

Tirado Mejía, Álvaro, "Las relaciones entre la Iglesia y el Estado en Colombia”. Revista de la Universidad de Antioquia, 54, 210 (1987), 52-66. 